\title{
Factors Associated with Type 1 and Type 2 Diabetes in Infants in Kuwait
}

\author{
Nedaa A. Al-Khamees \\ Curriculum and Instruction Department, College of Education, Kuwait University, Audaylia, Kuwait \\ Email: nedaa_al@hotmail.com
}

How to cite this paper: Al-Khamees, N.A. (2018) Factors Associated with Type 1 and Type 2 Diabetes in Infants in Kuwait. Health, 10, 1474-1486

https://doi.org/10.4236/health.2018.1011113

Received: October 13, 2018

Accepted: November 12, 2018

Published: November 15, 2018

Copyright (C) 2018 by author and Scientific Research Publishing Inc. This work is licensed under the Creative Commons Attribution-NonCommercial International License (CC BY-NC 4.0). http://creativecommons.org/licenses/by-nc/4.0/

\begin{abstract}
Purpose: The purpose of the study is to investigate the factors associated with diabetes and its influence on the prevalence of diabetes in Kuwait. Methods. A questionnaire was designed to explore the relationships between various factors and diabetes in children. The survey included 300 mothers of children up to five years of age in Kuwait and the results were subjected to a two-way contingency table analysis. Results. Variables showing at least a medium effect and a linear relationship are herein reported. Increasing maternal age was found to be related to the increasing prevalence of type 1 diabetes. An association between a higher prevalence of both type 1 and type 2 diabetes in the mother and the child was found. Risk of having a child with diabetes increases with the maternal age. The consumption of fried food or fast food by a child was associated with a higher prevalence of both type 1 and type 2 diabetes. Sugar consumption, both by the mother during pregnancy and by the child, was associated with a higher prevalence of type 2 diabetes. Heavy consumption of nuts by the child was associated with a higher prevalence of type 2. Conclusion: Genetics and environmental factors including diet may play important roles in the causation of both type 1 and type 2 diabetes in Kuwait.
\end{abstract}

\section{Keywords}

Type 1 Diabetes, Type 2 Diabetes, Children, Kuwait

\section{Introduction}

Diabetes is a chronic disease that is posing a great challenge to the health services. It is expected that the number of people who have diabetes will increase to approximately 430 million by 2030 worldwide [1] [2]. Kuwait is ranked among the top 10 countries for the high prevalence of diabetes in the world [3]. In 2017, 441.000 cases of diabetes were reported in Kuwait (International Diabetes Fed- 
eration).

Though genetic susceptibility is undoubtedly important in the development of type 1 diabetes, the majority of the genetically predisposed do not develop the disease, suggesting the presence of some environmental triggers [4]. Role of a strong environmental component in the causation of type 1 diabetes is also suggested by the considerable increase in the incidence of diabetes in recent decades. For instance, the incidence of childhood type 1 diabetes in Australia has been doubled in the last 20 years, with the greatest increase in younger children with lower risk genes [5]. Evidence for most of the putative environmental risk factors proposed, including infections, dietary factors, air pollution, vaccines, the location of residence, family environment, and stress, is inconclusive [6]. However, the literature does support a possible role of environmental chemicals as triggers or accelerators of type 1 diabetes development [7]. It is presently undecided whether environmental factors trigger islet autoimmunity in genetically susceptible subjects, and accelerate the disease progression in islet autoantibody subjects, or both [8].

Type 2 diabetes is also increasing rapidly globally and is occurring at a younger age, including childhood [9]. There appears to be a complex interplay of genetic and environmental factors in type 2 diabetes. People with a family history of diabetes are likely to have diabetes two to six times more than those without a family history of diabetes [10]-[15].

Another study suggested a complementary role for behavioral and environmental factors that modulate the genetic susceptibility and diabetes risk [16]. It is, however, usually considered that lifestyle factors, especially nutrition and exercise are of primary importance in the development of type 2 diabetes. Also, some environmental factors, including chemicals, vaccines, and electromagnetic radiation have been studied for a possible role in causation.

The present study was conducted to examine the factors associated with the causation of types 1 and 2 diabetes and its influence on the prevalence of diabetes in Kuwaiti children.

\section{Methodology}

\subsection{Participants}

The study included the mothers of children aged $\leq 5$ years. The mothers were reached out from social gatherings and diabetes clinics in government hospitals at different districts of Kuwait.

Clinics within each governate were selected with probability proportional to governate size. Participants within each governate clinics and gatherings were then selected by systematic equal probability sampling. Mothers of participated children were contacted in person; the concept of the study was explained to them. The mothers who were able to understand the instructions and willing to participate in the study were included. Participation was anonymous and voluntary. Permission was granted from the head of the participated hospitals and 
clinics and the hosts of the gatherings.

\subsection{Objective/Hypothesis}

The objective of the study was to investigate the risk factors which could correlate with the incidence of diabetes in children.

\subsection{Characteristics of the Questionnaire}

Based on the review of previous studies related to the risk factors of diabetes, all the possible factors (genetics, environmental, lifestyle) was collected and after appropriate modifications, a questionnaire was designed including 37 detailed questions exploring the relationship of various factors to the presence or absence of diabetes in a child which include :Genetic factors (mother, father, relatives, are diabetic), mother-related factors (age, weight, health status, quality of their food, their health during pregnancy ...), child-related factors (birth weight, the current health of the child, baby food quality, commitment to vaccinations, practicing sports activities ...). Environmental factors (the presence of electrical devices in the child's bedroom, the proximity of industrial areas, the use of pesticides, air fresheners, incense ...).

The questionnaire was evaluated and modified by four professors at Kuwait University and Public Authority for Applied Education.

A pilot study was carried by distributing questionnaires to 30 mothers divided equally between diabetes child and non-diabetes child, based on the results obtained; minor changes were made for some questions to improve comprehension.

\subsection{Survey}

A total of 300 copies of the questionnaire were distributed to the mothers of in different areas of Kuwait. The specially trained employees were hired to distribute and collect questionnaires after explaining the subject to the respondents and answering all the respondents' inquiry. For non-diabetes children, the hired employees went to different social gatherings in different districts and for diabetes children; they went to diabetes clinics in government hospitals in different areas of Kuwait. The females were asked if they have children up to 5 years of age. If they had more than one child of $<5$ years of age, mothers were asked to relate the questions only to their eldest child.

A written or verbal consent from the mothers was taken to participate in the study. To ensure privacy, names were not recorded. A statement stating "all information provided is treated as confidential and will not be released by the researcher to a third party and cannot identify them explicitly or implicitly" was included in the questionnaire.

\subsection{Statistical Analysis}

The completed questionnaires were analyzed by a statistician using a two-way 
contingency table analysis. Only results showing at least a medium-size effect and a linear relationship were considered further.

\section{Results}

\subsection{Participants}

A total of 300 mothers were surveyed, of whom $125(41.7 \%)$ had a type 1 diabetes child and 35 mothers had one with type 2 diabetes. Of the 160 diabetes children, 77 (25.7\%) were male, and 83 (27.7\%) were female. In 76 (47.5\%) children diabetes was diagnosed before three years of age, while in 84 (52.5\%) children diabetes was diagnosed after 3 years of age.

Participants were spread over the 6 governorates of Kuwait. Hawalli was underrepresented, while Mubarak Al-Kabir overrepresented. The children with type 1 diabetes were more in Farwania and Jahra governorates (Table 1).

\subsection{Prevalence of Diabetes in the Parents}

In total, 28 (9.3\%) mothers reported having type 1 diabetes, and 15 (5.0\%) reported type 2 diabetes, while 54 (18\%) of fathers had diabetes [Table 1].

1) Factors associated with mothers (Table 2)

Table 1. The sociodemographic and clinical characteristics of participants.

\begin{tabular}{|c|c|c|c|c|c|}
\hline \multicolumn{3}{|c|}{ Characteristics of Participated Mothers } & \multicolumn{3}{|c|}{ Characteristics of Participated Children } \\
\hline & Frequency & Percentage \% & & Frequency & Percentage \% \\
\hline \multicolumn{3}{|c|}{ Governorate } & \multicolumn{3}{|c|}{ Child's Birth Weight } \\
\hline Kuwait City & 49 & 16.3 & Less than normal & 36 & 12.0 \\
\hline Hawalli & 23 & 7.7 & Normal & 246 & 82.0 \\
\hline Farwania & 44 & 14.7 & More than normal & 18 & 6.0 \\
\hline Mubarak Al-Kabir & 48 & 16.0 & \multirow{2}{*}{\multicolumn{3}{|c|}{ Child hospitalized before the age of One Year due to Serious Infection }} \\
\hline Jahra & 45 & 15.0 & & & \\
\hline Al-Ahmadhi & 91 & 30.3 & Yes & 64 & 21.3 \\
\hline \multicolumn{3}{|c|}{ Mother's Education } & No & 236 & 78.7 \\
\hline Up to Secondary & 97 & 32.3 & \multicolumn{3}{|c|}{ Child Suffered from Asthma } \\
\hline Diploma or More & 203 & 67.7 & Yes & 83 & 27.7 \\
\hline \multicolumn{3}{|c|}{ Mother's Age } & No & 217 & 72.3 \\
\hline Up to 25 & 60 & 20.0 & \multicolumn{3}{|c|}{ The child has all the Recommended Vaccination } \\
\hline $26-35$ & 138 & 46.0 & Yes & 281 & 93.7 \\
\hline More than 35 & 102 & 34.0 & No & 19 & 6.3 \\
\hline \multicolumn{3}{|c|}{ Mother's Weight } & \multicolumn{3}{|c|}{ The child had Other Vaccinations } \\
\hline Healthy Weight & 147 & 49.0 & Yes & 21 & 7.0 \\
\hline Overweight & 153 & 51.0 & No & 279 & 93.0 \\
\hline \multicolumn{3}{|c|}{ Health Problems During Pregnancy } & \multicolumn{3}{|c|}{ Child's Participation in Sports Activities } \\
\hline
\end{tabular}




\section{Continued}

\begin{tabular}{|c|c|c|c|c|c|}
\hline Yes & 121 & 40.3 & Low & 95 & 31.7 \\
\hline No & 179 & 59.7 & Average & 148 & 49.3 \\
\hline \multirow{2}{*}{\multicolumn{3}{|c|}{$\begin{array}{l}\text { Types of Health Problems During Pregnancy } \\
\text { (Can have more than one problem) }\end{array}$}} & High & 57 & 19.0 \\
\hline & & & \multicolumn{3}{|c|}{ Child's Hypothyroid } \\
\hline Gestational Diabetes & 62 & & Yes & 14 & 4.7 \\
\hline Large Weight Increase & 37 & & No & 286 & 95.3 \\
\hline Severe Nausea & 29 & & \multicolumn{3}{|c|}{ Environmental Factors } \\
\hline Other Digestive Disorder & 16 & & & iving & \\
\hline Infection & 3 & & Electrical Generator & 84 & 28.0 \\
\hline Pre-eclampsia & 2 & & Communication Tower & 38 & 12.7 \\
\hline Other Disorder & 22 & & Electricity Tower & 22 & 7.3 \\
\hline \multicolumn{3}{|c|}{ Vaccination Immediately Before or During Pregnancy } & Gas Station & 73 & 24.3 \\
\hline Yes & 56 & 18.7 & Garbage Dump & 31 & 10.3 \\
\hline No & 244 & 81.3 & Industrial Area & 56 & 18.7 \\
\hline \multicolumn{3}{|c|}{ Type of Vaccine } & \multicolumn{3}{|c|}{ Use of Insecticides } \\
\hline Hepatitis & 5 & 1.7 & Rarely & 150 & 50.0 \\
\hline Influenza & 21 & 7.0 & Sometimes & 117 & 39.0 \\
\hline Other & 30 & 10.0 & Often & 33 & 11.0 \\
\hline \multicolumn{3}{|c|}{ Mothers Diabetic } & \multicolumn{3}{|c|}{ Use of Incense } \\
\hline Yes & 43 & 14.3 & Rarely & 17 & 5.7 \\
\hline No & 257 & 85.7 & Sometimes & 75 & 25.0 \\
\hline \multicolumn{3}{|c|}{ Type of Diabetic } & Always & 208 & 69.3 \\
\hline Type 1 & 28 & 9.3 & \multicolumn{3}{|c|}{ Use of Air Fresheners } \\
\hline Type 2 & 15 & 5.0 & Rarely & 56 & 18.7 \\
\hline \multicolumn{3}{|c|}{ First Degree Relative of Mother's Diabetic } & Sometimes & 100 & 33.3 \\
\hline Yes & 207 & 69.0 & Often & 144 & 48.0 \\
\hline No & 93 & 31.0 & & & \\
\hline \multicolumn{6}{|c|}{ Father's Diabetic } \\
\hline Yes & 54 & 18.0 & & & \\
\hline No & 246 & 82.0 & & & \\
\hline \multicolumn{6}{|c|}{ Father's Relative Diabetic } \\
\hline Yes & 191 & 63.7 & & & \\
\hline No & 109 & 36.3 & & & \\
\hline \multicolumn{6}{|c|}{ Mothers with Chronic Disorders } \\
\hline Liver Disorder & 7 & 2.3 & & & \\
\hline Kidney Disorder & 8 & 2.7 & & & \\
\hline Heart Disorder & 13 & 4.3 & & & \\
\hline
\end{tabular}


Table 2. Cross tabulation diabetic mother, age, sweets consumption during pregnancy and child diabetes.

\begin{tabular}{|c|c|c|c|c|c|c|c|}
\hline \multirow{2}{*}{\multicolumn{2}{|c|}{ Mother Diabetic }} & \multicolumn{2}{|c|}{ Child Type 1 Diabetic } & \multirow{2}{*}{ Total } & \multicolumn{2}{|c|}{ Child Type 2 Diabetic } & \multirow{2}{*}{ Total } \\
\hline & & Yes & No & & Yes & No & \\
\hline \multirow{2}{*}{ Not Diabetic } & Count & 101 & 132 & 233 & 24 & 132 & \\
\hline & Row \% & $43.3 \%$ & $56.7 \%$ & $100.0 \%$ & $15.40 \%$ & $84.60 \%$ & $100.00 \%$ \\
\hline \multirow{2}{*}{ Type 1 Diabetic } & Count & 15 & 5 & 20 & 8 & 5 & 13 \\
\hline & Row \% & $75.0 \%$ & $25.0 \%$ & $100.0 \%$ & $61.50 \%$ & $38.50 \%$ & $100.00 \%$ \\
\hline \multirow{2}{*}{ Type 2 Diabetic } & Count & 9 & 3 & 12 & 3 & 3 & 6 \\
\hline & Row \% & $75.0 \%$ & $25.0 \%$ & $100.0 \%$ & $50.00 \%$ & $50.00 \%$ & $100.00 \%$ \\
\hline \multicolumn{8}{|c|}{$\begin{array}{l}\text { Type 1: Pearson Chi-Square }=11.312 ; \mathrm{df}=2 ; \mathrm{P}=0.003, \text { Cramer V }=0.2 \\
\text { Type 2: Pearson Chi-Square }=19.471 ; \mathrm{df}=2 ; \mathrm{P}<0.0001, \text { Cramer V }=0.31\end{array}$} \\
\hline \multirow{2}{*}{\multicolumn{3}{|c|}{ Mother's Age }} & \multicolumn{3}{|c|}{ Child is Type 1 Diabetic } & \multirow{2}{*}{\multicolumn{2}{|c|}{ Total }} \\
\hline & & & & & No & & \\
\hline \multirow{2}{*}{ Up to 25} & \multicolumn{2}{|r|}{ Count } & \multicolumn{2}{|c|}{16} & 39 & \multicolumn{2}{|r|}{55} \\
\hline & & Row \% & \multicolumn{2}{|c|}{$29.1 \%$} & $70.9 \%$ & \multicolumn{2}{|r|}{$100.0 \%$} \\
\hline \multirow{2}{*}{$26-35$} & & Count & \multicolumn{2}{|c|}{58} & 60 & \multicolumn{2}{|r|}{118} \\
\hline & & Row $\%$ & \multicolumn{2}{|c|}{$49.2 \%$} & $50.8 \%$ & \multicolumn{2}{|r|}{$100.0 \%$} \\
\hline \multirow{2}{*}{ More than 35} & & Count & \multicolumn{2}{|c|}{51} & 41 & \multicolumn{2}{|r|}{92} \\
\hline & & Row \% & \multicolumn{2}{|c|}{$55.4 \%$} & $44.6 \%$ & \multicolumn{2}{|r|}{$100.0 \%$} \\
\hline \multicolumn{8}{|c|}{ Pearson Chi-Square $=9.922 ; \mathrm{df}=2 ; \mathrm{P}=0.007$, Cramer $\mathrm{V}=0.19$} \\
\hline \multirow{2}{*}{\multicolumn{3}{|c|}{ Mother's Sweets Consumption }} & \multicolumn{3}{|c|}{ Child Type 2 Diabetic } & \multirow{2}{*}{\multicolumn{2}{|c|}{ Total }} \\
\hline & & & Yes & & No & & \\
\hline & & Count & 3 & & 26 & & 29 \\
\hline & & Row \% & $10.30 \%$ & & $89.70 \%$ & & $100.00 \%$ \\
\hline Occasis & & Count & 11 & & 74 & & 85 \\
\hline & & Row \% & $12.90 \%$ & & $87.10 \%$ & & $100.00 \%$ \\
\hline & & Count & 21 & & 40 & & 61 \\
\hline Silt & & Row \% & $34.40 \%$ & & $65.60 \%$ & & $100.00 \%$ \\
\hline & & Chi-Squa & $71 ; \mathrm{df}=2$ & Sig. $=$ & 02, Cramer $\mathrm{V}=$ & & \\
\hline
\end{tabular}

\section{a) Diabetic mother.}

It was found that mothers with either type 1 or type 2 diabetes were more likely to have a child with either form of diabetes.

Of the 28 mothers with type 1 diabetes, 15 had a child with type 1 diabetes, 8 had a child with type 2 diabetes, and 5 did not have a child with diabetes. Of the 15 mothers with type 2 diabetes, 9 had a child with type 1 diabetes, 3 had a child with type 2 diabetes, and 3 had a child who did not have diabetes. Mothers with type 1 diabetes were found to be significantly more likely to have children with type 1 diabetes as well as type 2 diabetes.

\section{b) Mother's Age}


There was a significantly lower likelihood of mothers of age $\leq 25$ years having a child with type 1 diabetes.

\section{c) Diet of Mother}

Overall, all mothers ate good quantities of dairy products and moderate amounts of other common foods. It was found that those who ate large quantities of nuts or sweets were significantly more likely to have a child with type 2 diabetes. Sugar consumption was linked to type 2 diabetes when ingested by the mother during pregnancy.

- 50 (16.7\%) mothers have more than one diabetic child, 110 (36.7\%) mothers have only one diabetic child.

- 223 (74.3\%) mothers used to breastfeed their child whereas 77 (25.7\%) mothers did not breastfeed their child.

- 90 (30.0\%) mothers breastfed their child for "less than 3 months", 73 (24.3\%) mothers breastfed their child for " 3 - 6" months, 60 (20.0\%) mothers breastfed their child for "more than 6 months". 77 (25.7\%) mothers did not breastfeed their child.

- $81(27 \%)$ mothers gave fresh milk to their child before the age of 6 months.

- 75 (25\%) mothers gave solid food to their child before the age of 6 months.

\section{d) Mother's Chronic Conditions}

Broadly classified, chronic conditions were identified as disorders of the liver $(\mathrm{n}=7,2.3 \%)$, kidney $(\mathrm{n}=8,2.7 \%)$, heart $(\mathrm{n}=13,4.3 \%)$ and thyroid $(\mathrm{n}=51$, $17 \%)$. The analysis found that mothers with disorders of the liver were significantly more likely to have a child with type 2 diabetes $(57.10 \%, \mathrm{p}=0.012)$ while a correlation was found between the presence of a disorder of the heart in the mother and type 1 diabetes $(80 \%, \mathrm{p}=0.034)$ and also type 2 diabetes $(60 \%, \mathrm{p}=$ $0.023)$. Mothers with thyroid dysfunction were also significantly more likely to have a type 1 or type 2 diabetes child.

Also, diabetic mothers either with type 1 or type 2 , both were significantly more likely to have a type 1 or type 2 diabetes child.

\section{e) Mother's weight}

Perhaps not unexpectedly, overweight mothers were found to be significantly more liable to have a child with type 2 diabetes $(26.4 \%, \mathrm{p}=0.028)$.

\section{f) Vaccination during pregnancy}

If the mother was vaccinated just before or during pregnancy, her baby was significantly more likely to develop type 2 diabetes $(33.30 \%, \mathrm{p}=0.045)$.

2) Factors associated with a child

\section{a) Diet of a child}

Sugar consumption was linked to type 2 diabetes when digested by a child. Consumption of fried food and fast foods by the child were associated with a higher prevalence of both type 1 and type 2 diabetes, while a significant relationship between consumption of nuts and type 2 diabetes was found (Table 3 ).

\section{b) Child's illness}

A child who was hospitalized during his or her first year of life with a serious acute infection was significantly more likely to suffer from type 1 diabetes 
(64.9\%, $\mathrm{p}=0.002)$, as was a hypothyroid child $(76.9 \%, \mathrm{p}=0.028)$. On the other hand, a correlation was found between the child suffering from asthma and having type 2 diabetes $(34 \%, p=0.002)$. According to the analysis, a child who had received all the recommended vaccinations was also at significantly greater risk of being type 2 diabetes $(17.4 \%, \mathrm{p}=0.003)$. The table below shows the child's food consumption.

\section{c) Child Birth Weight}

Children with below average birth weight were significantly more likely to be type 1 diabetes $66.70 \%, p=0.010$ while those above normal were substantially more likely to have type 2 diabetes $55.6 \%, \mathrm{p}=0.022$.

\section{d) Location of residence}

Children living near a communication tower were significantly more likely to have type 1 diabetes $(65.60 \%, \mathrm{p}=0.026)$, while those living near an electrical tower $(64.3 \%, \mathrm{p}=0.0001)$ or living in a house where insecticides were regularly used were significantly more likely to have diabetes type $2(38.1 \%, \mathrm{p}=0.002)$.

\section{e) Use of Insecticides, incense or air fresheners}

A total of $11 \%$ of children were often exposed to insecticides. Majority of children were always exposed to incense (69\%) and air fresheners (48\%).

\section{f) Electrical Appliances}

Majority of children (70.3\%) were exposed to electrical appliances that were operational constantly in the child's rooms.

\section{g) Sports Activities of child}

The majority of children participated more or less regularly in some sports activity. Those children (31.7\%) who did not involve themselves in sports activity were significantly more likely to have type 1 diabetes $(61.80 \%, \mathrm{p}=0.002)$.

Table 3. Cross tabulation of child's consumption for different types of food and child diabetes.

\begin{tabular}{|c|c|c|c|c|c|c|c|c|c|c|c|c|c|}
\hline & & \multirow{2}{*}{\multicolumn{2}{|c|}{$\begin{array}{l}\text { Sugar and Sweets } \\
\text { Type } 2 \text { Diabetes }\end{array}$}} & \multicolumn{4}{|c|}{ Fried Food } & \multicolumn{4}{|c|}{ Fast Food } & \multirow{2}{*}{\multicolumn{2}{|c|}{$\begin{array}{c}\text { Nuts } \\
\text { Type } 2 \text { Diabetes }\end{array}$}} \\
\hline & & & & \multicolumn{2}{|c|}{ Type 1 Diabetes } & \multicolumn{2}{|c|}{ Type 2 Diabetes } & \multicolumn{2}{|c|}{ Type 1 Diabetes } & \multicolumn{2}{|c|}{ Type 2 Diabetes } & & \\
\hline & & Yes & No & Yes & No & Yes & No & Yes & No & Yes & No & Yes & No \\
\hline \multirow{4}{*}{ Occasionally } & Count & 2 & 15 & 14 & 37 & 5 & 43 & 18 & 43 & 5 & 43 & 11 & 65 \\
\hline & Row \% & $11.80 \%$ & $88.20 \%$ & $27.50 \%$ & $72.50 \%$ & $10.40 \%$ & $89.60 \%$ & $29.50 \%$ & $70.50 \%$ & $10.40 \%$ & $89.60 \%$ & $14.50 \%$ & $85.50 \%$ \\
\hline & Count & 8 & 67 & 43 & 67 & 14 & 67 & 47 & 67 & 14 & 67 & 10 & 60 \\
\hline & Row \% & $10.70 \%$ & $89.30 \%$ & $39.10 \%$ & $60.90 \%$ & $17.30 \%$ & $82.70 \%$ & $41.20 \%$ & $58.80 \%$ & $17.30 \%$ & $82.70 \%$ & $14.30 \%$ & $85.70 \%$ \\
\hline \multirow{7}{*}{ Often } & Count & 25 & 58 & 68 & 36 & 16 & 30 & 60 & 30 & 16 & 30 & 14 & 15 \\
\hline & Row \% & $30.10 \%$ & $69.90 \%$ & $65.40 \%$ & $34.60 \%$ & $34.80 \%$ & $65.20 \%$ & $66.70 \%$ & $33.30 \%$ & $34.80 \%$ & $65.20 \%$ & $48.30 \%$ & $51.70 \%$ \\
\hline & & \multicolumn{2}{|c|}{ Pearson } & \multicolumn{2}{|c|}{ Pearson } & \multicolumn{2}{|c|}{ Pearson } & \multicolumn{2}{|c|}{ Pearson } & \multicolumn{2}{|c|}{ Pearson } & \multicolumn{2}{|c|}{ Pearson } \\
\hline & & \multicolumn{2}{|c|}{ Chi-Square $=10.117$} & \multicolumn{2}{|c|}{ Chi-Square $=24.685 ;$} & \multicolumn{2}{|c|}{ Chi-Square $=6.955 ;$} & \multicolumn{2}{|c|}{ Chi-Square $=22.979$} & \multicolumn{2}{|c|}{ Chi-Square $=9.411 ;$} & Chi-Squar & $=17.371$ \\
\hline & & \multicolumn{2}{|c|}{$\mathrm{df}=2$} & \multicolumn{2}{|c|}{$\mathrm{df}=2$} & \multicolumn{2}{|c|}{$\mathrm{df}=2$} & \multicolumn{2}{|c|}{$\mathrm{df}=2$} & \multicolumn{2}{|c|}{$\mathrm{df}=2$} & \multicolumn{2}{|c|}{$\mathrm{df}=2$} \\
\hline & & \multicolumn{2}{|c|}{ Asymp. $\mathrm{P}=0.006$} & \multicolumn{2}{|c|}{ Asymp. $\mathrm{P}<0.0001$} & \multicolumn{2}{|c|}{ Asymp. $\mathrm{P}=0.031$} & \multicolumn{2}{|c|}{ Asymp. $\mathrm{P}<0.0001$} & \multicolumn{2}{|c|}{ Asymp. $\mathrm{P}=0.009$} & \multicolumn{2}{|c|}{ Asymp. P. $<0.0001$} \\
\hline & & \multicolumn{2}{|c|}{$\mathrm{V}=0.24$} & \multicolumn{2}{|c|}{ Cramer V $=0.20$} & Cramer & $V=0.199$ & Cramer & $V=0.29$ & $\mathrm{~V}=$ & 0.23 & Cramer & $=0.315$ \\
\hline
\end{tabular}




\section{Discussion}

Diabetes is a major public health problem in Kuwait. The incidence of type 1 diabetes in Kuwaiti children of age 0 - 14 years has doubled in the last 2 decades. Further investigation to find out the reasons for this increase is suggested [17].

In this survey, several factors were measured that might be associated with diabetes. The results of the survey support that along with the hereditary factors; there are some environmental factors that may play a major role in causing diabetes. Factors such as family history, the age of mother, diet were found to be highly associated with both types of diabetes in children.

The major paradigms: genetic risk variants and behavioral/environmental/ lifestyle factors jointly underlie diabetes development [16]. Altobelli et al., investigated the role of genetic and environmental factors that affect the onset of diabetes type 1 in patients < 15 years of age. In all age groups, a significant rising trend was observed for the overall population $(3.40 \%, \mathrm{p}<0.01)$ and for $5-9 \mathrm{yr}$. olds $(5.48 \%, \mathrm{p}<0.01)$. Mixed feeding and a family history of diabetes were associated with early onset of diabetes, while multiple bacterial infections contracted before diabetes was associated with a significant delay [18].

Family history, BMI, and sex are the established risk factors of diabetes. In a study by Channanath, et al., 32\% of diabetes patients have a family history of diabetes and/or hypertension [19]. A child with a family history of diabetes is more likely to have type 1 or 2 diabetes. In the present study, type 1 or type 2 diabetes mother had exactly the same chance of having a child with type 1 diabetes, however, if she was type 1 diabetes, there was a greater chance of having a child with type 2 diabetes.

In the current survey, diabetes was also found to be associated with the mother's age. The research to find the role of maternal age in onset type 1 diabetes in childhood began during 1960s with the analysis of case studies [20]. Recently, this association was studied in cohort studies and has received much attention [20] [21] [22]. However, conflicting results were obtained, and the results are difficult to interpret due to the different sizes and power of the studies and the different ways of reporting the association [22] [23] [24] [25]. According to the analysis of current data, older mothers are significantly more likely to have a child with type 1 diabetes. Cardwell et al. conducted a pooled analysis of 30 observational studies to investigate whether children born to older mothers have an increased risk of type 1 diabetes. Overall, there was a $5 \%$ increase in childhood type 1 diabetes odds per 5-year increase in maternal age, but there was heterogeneity among studies. There is nearly $20 \%$ difference in the risk of type 1 diabetes, across the maternal age range. Though the evidence was weak but significant linear increase in the risk of childhood type 1 diabetes with maternal age was observed. However, in recent years a very small increase in the incidence of childhood diabetes type 1 could be explained by increases in maternal age [25]. If this were borne out, it could partly explain the rise in type 1 diabetes in some countries given a steady increase in mother's age when giving birth. 
Low physical activity levels, poor diet, and excess body weight are the major contributory factors for type 2 diabetes mellitus in Middle Eastern countries including Kuwait [26]. Eating large portions and frequent eating out is the cause of diabetes in Kuwait. The results of this study indicate that heavy consumption of sweets by the pregnant mother or by the child as a risk factor for type 2 diabetes in the child, and consumption of fried foods or fast foods by the child are risk factors for both type 1 and type 2 diabetes. These risks do not appear to have been previously reported earlier. However, the consensus view appears that sugar and fats act through increasing obesity. The large effect observed of the increase in the prevalence of type 2 diabetes in children with high consumption of nuts is anomalous, since nuts are usually regarded as beneficial in diabetes

A cross-sectional study conducted on all hospital admissions in the Department of Medicine at Al-Sabah Hospital in Kuwait reported diabetes as the principal or secondary diagnosis in $40.6 \%$ of hospitalizations [27]. A marked increase in the incidence of diabetes during recent decades also suggest the involvement of environmental factors and, as the peak incidence of diabetes occurs in late childhood; it is thought that the exposures in early life could play an important role [25] [28]. Similarly, the findings from another study showed that environmental factors play an important role in the etiology of type 1 diabetes [29]. In the current study, residence and exposure to certain chemicals were found to be associated with diabetes.

The course metabolic control of diabetes is affected by many factors related to lifestyles such as physical activity and the availability and quality of medical care. The residing place of the patient also matters as it determines the healthcare and specialist availability, therapy, education, and also the degree of patient adherence to medical recommendations [2]. Hospital outpatient preventive and treatment strategies and effective primary care may reduce the burden of diabetes in Kuwait [27].

The numbers are too small for firm conclusions, but the results suggest the possibility of complex interactions in the causation of both types.

The survey had certain limitations. Firstly, the relatively small sample size that may not be truly representative of the whole population of children with diabetes. Secondly, the presence of unaccounted-for confounding factors. In future, the assessment of a sample that would be a true representative for the population, i.e., examination large group of people with a random selection of subjects suffering from type 1 and type 2 diabetes is advisable.

\section{Conclusions}

In Kuwait diabetes is imposing a great burden on health care utilization. Both genetic and environmental factors are associated with diabetes in Kuwait. Type 1 and type 2 diabetes may be more closely connected than generally acknowledged. Among all the factors examined in the survey, family history, mother's age and diet of mother and a child were the most significant factors associated with the causation of either type 1 or 2 diabetes. 
Based on the results of the current survey some considerations may be suggested to reduce the incidence of diabetes in children which include:

- The importance of nutrition for both the pregnant mother and the child in terms of reducing sweets, fried and fast food as much as possible and not over-eating nuts.

- The importance of the mother's health: if a mother has a chronic illness such as diabetes, heart disease, thyroid disorder, or liver disorder, or if she is overweight, she should consider her health before and during pregnancy, considering the medical and nutritional requirements, besides maintaining healthy body weight.

- A special consideration for the health of the child, especially if he had asthma or acute infection required hospitalization during his first year of life.

- Keep the child participating regularly in some sport activities.

- It is advised to reduce using insecticides in a house and to avoid housing near communication towers or electricity towers.

It is hoped that these results will help to guide health promotion and education on the topic in Kuwait and would promote future research. In order to attain greater success, a more extensive initiative is required, may be in the form of programs, and resources to address the health needs that have been identified in this study.

\section{Funding Acknowledgment}

The research was supported by Kuwait University (Grant Number TT03/16).

\section{Conflicts of Interest}

The author declares that there is no conflict of interest.

\section{References}

[1] Shaw, J.E., Sicree, R.A. and Zimmet, P.Z. (2010) Global Estimates of the Prevalence of Diabetes for 2010 and 2030. Diabetes Research and Clinical Practice, 87, 4-14. https://doi.org/10.1016/j.diabres.2009.10.007

[2] Dudzińska, M., Tarach, J.S., Zwolak, A., Kurowska, M., Malicka, J., Smoleń, A., et al. (2013) Type 2 Diabetes Mellitus in Relation to Place of Residence: Evaluation of Selected Aspects of Socio-Demographic Status, Course of Diabetes and Quality of Life: A Cross-Sectional Study. Annals of Agricultural and Environmental Medicine, 20, 869-874.

[3] Abuyassin, B. and Laher, I. (2016) Diabetes Epidemic Sweeping the Arab World. World Journal of Diabetes, 7, 165-174. https://doi.org/10.4239/wjd.v7.i8.165

[4] Couper, J.J. (2001) Environmental Triggers of Type 1 Diabetes. Journal of Paediatrics and Child Health, 37, 218-220. https://doi.org/10.1046/j.1440-1754.2001.00658.x

[5] Penno, M.A., Couper, J.J., Craig, M.E., Colman, P.G., Rawlinson, W.D., Cotterill, A.M., et al. (2013) Environmental Determinants of Islet Autoimmunity (ENDIA): A Pregnancy to Early Life Cohort Study in Children At-Risk of Type 1 Diabetes. BMC Pediatrics, 13, 124-138. https://doi.org/10.1186/1471-2431-13-124 
[6] Butalia, S., Kaplan, G.G., Khokhar, B. and Rabi, D.M. (2016) Environmental Risk Factors and Type 1 Diabetes: Past, Present, and Future. Canadian Journal of Diabetes, 40, 586-593. https://doi.org/10.1016/j.jcjd.2016.05.002

[7] Bodin, J., Stene, L.C. and Nygaard, U.C. (2015) Can Exposure to Environmental Chemicals Increase the Risk of Diabetes Type 1 Development? BioMed Research International, 2015, Article ID: 208947. https://doi.org/10.1155/2015/208947

[8] Regnéll, S.E. and Lemmark, A. (2013) The Environment and the Origins of Islet Autoimmunity and Type 1 Diabetes. Diabetic Medicine, 30, 155-160. https://doi.org/10.1111/dme.12099

[9] Silink, M. (2002) Childhood Diabetes: A Global Perspective. Hormone Research, 57, $1-5$.

[10] Ali, B.A., Abdallah, S.T., Abdallah, A.M. and Hussein, M.M. (2013) The Frequency of Type 2 Diabetes Mellitus among Diabetic Children in El Minia Governorate, Egypt. Sultan Qaboos University Medical Journal, 13, 399-403.

[11] Azzopardi, P., Brown, A.D., Zimmet, P., Fahy, R.E., Dent, G.A., Kelly, M.J., et al. (2012) Type 2 Diabetes in Young Indigenous Australians in Rural and Remote Areas: Diagnosis, Screening, Management, and Prevention. The Medical Journal of Australia, 197, 32-36. https://doi.org/10.5694/mja12.10036

[12] Diabetes, U.K. (2012) Diabetes in the UK 2011/2012: Key Statistics on Diabetes. www.diabetes.org.uk/Documents/Reports/Diabetes-in-the-UK-2-122-12/pdf

[13] Moussa, M.A., Alsaeid, M., Abdella, N., Refai, T.M., Al-Sheikh, N. and Gomez, J.E. (2008) Prevalence of Type 2 Diabetes Mellitus among Kuwaiti Children and Adolescents. Medical Principles and Practice, 17, 270-275. https://doi.org/10.1159/000129604

[14] Punnose, J., Agarwal, M.M. and Bin-Uthman, S. (2005) Type 2 Diabetes Mellitus among Children and Adolescents in Al-Ain: A Case Series. Eastern Mediterranean Health Journal, 11, 788-797.

[15] Scott, L.K. (2013) Presence of Type 2 Diabetes Risk Factors in Children. Pediatric Nursing, 39, 190-196.

[16] Murea, M., Ma, L. and Freedman, B.I. (2012) Genetic and Environmental Factors Associated with Type 2 Diabetes and Diabetic Vascular Complications. The Review of Diabetic Studies, 9, 6-22. https://doi.org/10.1900/RDS.2012.9.6

[17] Shaltout, A.A., Wake, D., Thanaraj, T.A., Omar, D.M., Al-AbdulRazzaq, D., Channanath, A., et al. (2017) Incidence of Type 1 Diabetes Has Doubled in Kuwaiti Children 0-14 Years over the Last 20 Years. Pediatric Diabetes, 18, 761-766. https://doi.org/10.1111/pedi.12480

[18] Blasetti, A., Di Giulio, C., Tocco, A.M., Verrotti, A., Tumini, S., Chiarelli, F., et al. (2011) Variables Associated with Severe Hypoglycemia in Children and Adolescents with Type 1 Diabetes: A Population-Based Study. Pediatric Diabetes, 12, 4-10. https://doi.org/10.1111/j.1399-5448.2010.00655.x

[19] Channanath, A.M., Farran, B., Behbehani, K. and Thanaraj, T.A. (2013) Hypertension, and Comorbidity in Kuwait: Showcasing the Trends as Seen in Native versus Expatriate Populations. Diabetes Care, 36, e75. https://doi.org/10.2337/dc12-2451

[20] Struwe, F.E. (1960) On the Manifestation of Diabetes Mellitus in Childhood (Age of Manifestation, Maternal Age at Birth). Monatsschrift Kinderheilkunde, 108, 487-490.

[21] Dahlquist, G. and Kallen, B. (1992) Maternal-Child Blood Group Incompatibility and Other Perinatal Events Increase the Risk for Early-Onset Type-1 (Insulin Dependent) Diabetes Mellitus. Diabetologia, 35, 671-675. 
https://doi.org/10.1007/BF00400261

[22] Bock, T., Pedersen, C.R., Vølund, A., Pallesen, C.S. and Buschard, K. (1994) Perinatal Determinants among Children Who Later Develop IDDM. Diabetes Care, 17, 1154-1157. https://doi.org/10.2337/diacare.17.10.1154

[23] Patterson, C.C., Carson, D.J., Hadden, D.R., Waugh, N.R. and Cole, S.K. (1994) A Case-Control Investigation of Perinatal Risk Factors for Childhood IDDM in Northern Ireland and Scotland. Diabetes Care, 17, 376-381.

https://doi.org/10.2337/diacare.17.5.376

[24] Rosenbauer, J., Herzig, P. and Giani, G. (2008) Early Infant Feeding and Risk of Type 1 Diabetes Mellitus-A Nationwide Population-Based Case-Control Study in Pre-School Children. Diabetes/Metabolism Research and Reviews, 24, 211-222. https://doi.org/10.1002/dmrr.791

[25] Cardwell, C.R., Stene, L.C., Joner, G., et al. (2010) Maternal Age at Birth and Childhood Type 1 Diabetes: A Pooled Analysis of 30 Observational Studies. Diabetes, 59, 486-494. https://doi.org/10.2337/db09-1166

[26] Alsairafi, Z., Taylor, K., Smith, F. and Alattar, A. (2016) Patients' Management of Type 2 Diabetes in Middle Eastern Countries: Review of Studies. Patient Preference Adherence, 10, 1051-1062. https://doi.org/10.2147/PPA.S104335

[27] Al-Adsani Afaf, M.S. and Abdulla Kholouda, A. (2015) Reasons for Hospitalizations in Adults with Diabetes in Kuwait. International Journal of Diabetes Mellitus, 3, 65-69. https://doi.org/10.1016/j.ijdm.2011.01.008

[28] Patterson, C.C., Dahlquist, G.G., Gyurus, E., Green, A., Soltesz, G. and Eurodiab Study Group (2009) Incidence Trends for Childhood Type 1 Diabetes in Europe during 1989-2003 and Predicted New Cases 2005-20: A Multicentre Prospective Registration Study. The Lancet, 373, 2027-2033. https://doi.org/10.1016/S0140-6736(09)60568-7

[29] Akerblom, H.K., Vaarala, O., Hyöty, H., Ilonen, J. and Knip, M. (2002) Environmental Factors in the Etiology of Type 1 Diabetes. American Journal of Medical Genetics, 115, 18-29. https://doi.org/10.1002/ajmg.10340 